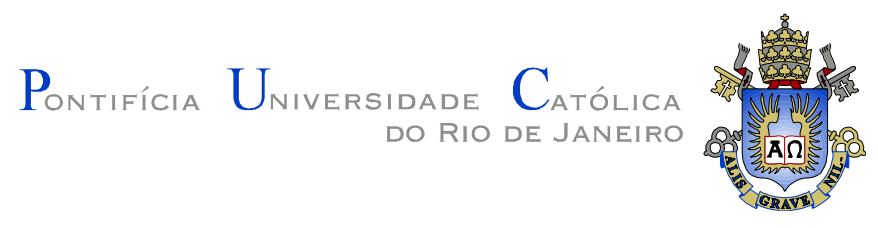

Ana Beatriz da Cunha Barreto

\title{
Avaliação de Recarga e de Sustentabilidade de Recursos Hídricos Subterrâneos de uma Micro-bacia usando Modelagem Numérica
}

Tese de Doutorado

Tese apresentada ao Programa de Pósgraduação em Engenharia Civil da PUC-Rio como requisito parcial para obtenção do título de Doutor em Engenharia Civil.

Orientador: Eurípedes do Amaral Vargas Junior Co-orientador: John Edward Gale

Rio de Janeiro, maio de 2010 


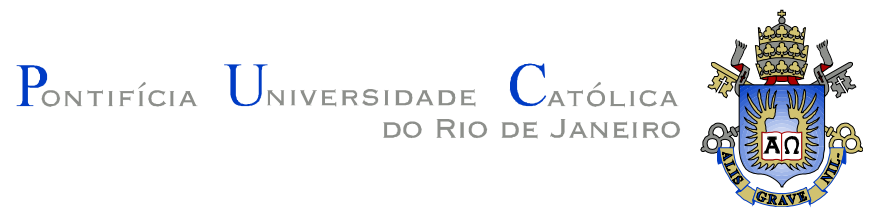

Ana Beatriz da Cunha Barreto

\section{Avaliação de Recarga e de Sustentabilidade de Recursos Hídricos Subterrâneos de uma Micro-Bacia usando Modelagem Numérica}

Tese apresentada como requisito parcial para obtenção do título de Doutor pelo Programa de Pós-Graduação em Engenharia Civil da PUCRio. Aprovada pela Comissão abaixo assinada.

Prof.Eurípedes do Amaral Vargas Júnior Orientador e Presidente Departamento de Engenharia Civil - PUC-Rio

Prof. José Tavares de Araruna Júnior Departamento de Engenharia Civil - PUC-Rio

Prof. George de Paula Bernardes UNESP-FEG

Prof. Nelson Ferreira Fernandes IG/UFRJ

\section{Prof. Otto Corrêa Rotunno Filho COPPE/UFRJ}

Prof. José Eugenio Leal

Coordenador Setorial do Centro Técnico Científico - PUC-Rio

Rio de Janeiro, 21 de maio de 2010 
Todos os direitos reservados. É proibida a reprodução total ou parcial do trabalho sem a autorização da universidade, da autora e do orientador.

\section{Ana Beatriz da Cunha Barreto}

Graduou-se em Geologia pela UFRJ em 1982 e obteve o título de Mestre em Engenharia Civil pela PUC-Rio. É professora da Faculdade de Geologia da UERJ e pesquisadora em geociências da CPRM/Serviço Geológico do Brasil, onde é responsável pela Divisão de Hidrogeologia e Exploração do Departamento de Hidrologia.

Ficha Catalográfica

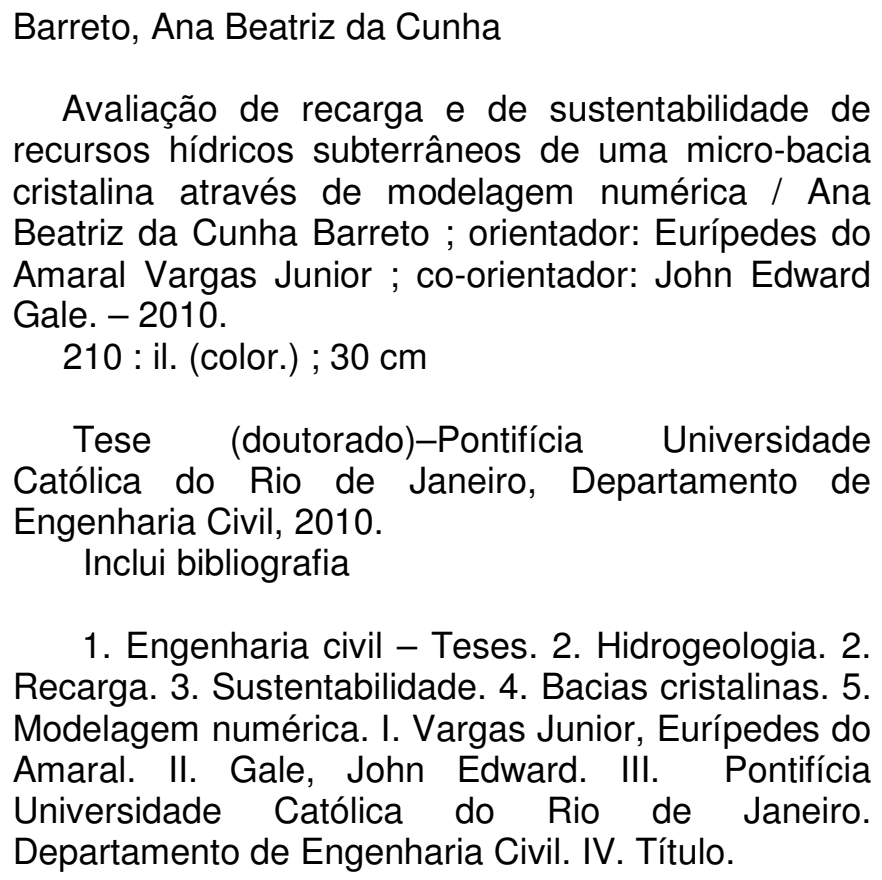
recursos hídricos subterrâneos de uma micro-bacia cristalina através de modelagem numérica / Ana Beatriz da Cunha Barreto ; orientador: Eurípedes do Amaral Vargas Junior ; co-orientador: John Edward Gale. - 2010. 210 : il. (color.) ; $30 \mathrm{~cm}$

Tese (doutorado)-Pontifícia Universidade Católica do Rio de Janeiro, Departamento de Engenharia Civil, 2010. Inclui bibliografia

1. Engenharia civil - Teses. 2. Hidrogeologia. 2. Recarga. 3. Sustentabilidade. 4. Bacias cristalinas. 5. Modelagem numérica. I. Vargas Junior, Eurípedes do Amaral. II. Gale, John Edward. III. Pontifícia Universidade Católica do Rio de Janeiro. Departamento de Engenharia Civil. IV. Título. 


\section{Agradecimentos}

Aos meus pais pelo amor e por serem as pessoas mais generosas que eu conheço, tendo me proporcionado todas as oportunidades na vida.

Ao Guilherme pelo riso e pela cumplicidade, pela paciência e amor e por tudo aquilo que faz a nossa convivência tão especial.

Aos meus orientadores Eurípedes do Amaral Vargas Junior e John Edward Gale, pelo incentivo, apoio e pelo exemplo de vida.

Às amigas Andrea, Jane, Raquel e Lígia pela ajuda e pelas idéias, que contribuíram tanto com essa Tese.

À Genevieve Gale que me acolheu como membro de sua família e fez o inverno na Terra Nova não parecer tão difícil.

À Rita de Cássia da civil, por sua bondade e atenção.

À CAPES pelo auxílio que possibilitou a execução de parte importante desta Tese.

À CPRM e à UERJ pelas licenças concedidas, sem as quais seria impossível a realização deste trabalho.

A todos os meus amigos e familiares pela convivência e pelo incentivo. 


\section{Resumo}

Barreto, Ana Beatriz da Cunha; Vargas Jr., Eurípedes do Amaral; Gale, John Edward. Avaliação da Recarga e de Sustentabilidade de Recursos Hídricos Subterrâneos de uma Micro-Bacia usando Modelagem Numérica. Rio de Janeiro 210p. Tese de Doutorado - Departamento de Engenharia Civil da Pontifícia Universidade Católica do Rio de Janeiro.

A avaliação da recarga subterrânea e de sua variação temporal e espacial, em bacias hidrográficas, é essencial para estudos de sustentabilidade de recursos hídricos e requer, na maior parte das vezes, o uso de um modelo numérico de fluxo 3D. Geralmente, dados como mapas geológicos e pedológicos estão disponíveis, a localização e geometria das principais feições estruturais podem ser identificadas a partir de imagens de satélite, em ambiente SIG, e dados de hidrologia superficial e de elevação de terreno são fáceis de conseguir. No entanto, para se utilizar um modelo numérico que forneça uma primeira avaliação da sustentabilidade de uma explotação, é necessário alimentá-lo com dados de propriedades hidráulicas consistentes com a faixa de valores representativos dos tipos de rocha que compõe a bacia. Uma revisão de dados hidrogeológicos de uma série de localidades mostra que, enquanto as propriedades hidráulicas das rochas fraturadas apresentam uma grande variação em seus valores, quando analisadas de forma indiscriminada, ao serem agrupadas por tipo litológico, apresentam uma faixa de variação mais restrita (i.e. granito fraturado vs. gabro fraturado). Há um grande volume de dados relativos a projetos de disposição de lixo radioativo, mineração e engenharia civil, em diversos sítios ao redor do mundo, em que foram feitas investigações detalhadas do meio fraturado. Dados de um determinado maciço fraturado podem ser usados em outro, não investigado, como uma primeira aproximação, desde que possuam o mesmo tipo litológico e pertençam a ambientes tectônicos semelhantes. Este tratamento foi utilizado para modelar a vazão sustentável de uma pequena bacia de drenagem no Noroeste Fluminense. Dados relativos às estruturas dominantes e aos sistemas de fraturas foram extraídos de imagens de satélite, fotos aéreas e de afloramentos, e tratados 
em ambiente SIG. O modelo de fluxo subterrâneo foi construído com dados de elevação do terreno, mapas geológicos, registros hidrológicos históricos bem como mapas pedológicos e de uso da terra. O programa FEFLOW (Diersch, 1998) foi usado para simular a distribuição espacial e temporal da recarga subterrânea na bacia e diferentes cenários de explotação de água subterrânea. O modelo mostrouse capaz de fornecer uma primeira aproximação das reservas subterrâneas da bacia e de avaliar a relação entre o fluxo subterrâneo e dos cursos d'água superficiais, em condições naturais e nos cenários de explotação, sendo assim uma ferramenta útil para análises de sustentabilidade de exploração destes recursos.

\section{Palavras-chave}

Hidrogeologia; recarga; sustentabilidade; bacias cristalinas; modelagem numérica. 


\section{Abstract}

Barreto, Ana Beatriz da Cunha; Vargas Jr., Eurípedes do Amaral (Advisor); Gale, John Edward (Co-advisor). Assessment of Groundwater Recharge and Sustainable Resources in a Small Crystalline Fractured Rock Drainage Basin with Numerical Modeling. Rio de Janeiro, 2010. 210p. Dsc. Thesis - Departamento de Engenharia Civil da Pontifícia Universidade Católica do Rio de Janeiro.

The estimation of groundwater recharge and its spatial and temporal variability in a drainage basin is essential for sustainability assessments and requires, in most cases, the use of an appropriate 3D numerical flow and transport model. For most drainage basins, the bedrock and overburden geology maps exist, the location and geometry of major structural features can be identified using available GIS databases, and surface water and terrain elevation data at an appropriate scale are readily available. In order to use 3D models to provide an initial assessment of the sustainability of the groundwater resource extraction of a specific drainage basin, the $3 \mathrm{D}$ model has to be populated with hydraulic properties that are consistent with the range of values that are representative of the rock types that underlie the drainage basin. A review of hydrogeological data from a number of sites shows that while there is a wide range in the hydraulic properties of fractured rocks in general, the range for individual rock types is more constrained, (i.e. fractured granite versus fractured gabbro). There is a great amount of hydrogeological data from fractured rock masses that have been investigated in detail as part of nuclear waste, mining and civil engineering projects around the world. Data from a specific site can be used as a first approach in another one, not investigated, once they have the same geologic characteristics and tectonic environment. This approach was used to model the sustainable groundwater yield of a small drainage basin in Southeast Brazil. Data on major structures and fracture systems were extracted from satellite images, aerial photos and outcrop expositions using GIS environment. The groundwater flow model was constructed using terrain elevation data, geology maps, hydrological records, 
as well as soil type and land use maps. FEFLOW (Diersch, 1988) was used to simulate the spatial and temporal distribution of groundwater recharge in the basin, using different pumping scenarios. The model was capable to yield a good estimation of groundwater resources in the watershed, as a first approach, and to assess groundwater and surface water relations in natural conditions and in stress scenarios being a useful tool for sustainability analysis of groundwater exploitation.

\section{Keywords}

Hydrogeology; recharge; sustainability; fractured rock watersheds; numerical modeling 


\section{Sumário}

$\begin{array}{ll}\text { 1. Introdução } & 14\end{array}$

1.1. Apresentação do problema 14

$\begin{array}{ll}\text { 1.2. Objetivos } & 17\end{array}$

$\begin{array}{ll}\text { 1.3. Justificativas } & 17\end{array}$

1.4. Organização da Tese 18

2. Recarga Subterrânea e Sustentabilidade 19

2.1. Recarga subterrânea 19

2.2. Metodologias de avaliação de recarga subterrânea 22

2.2.1 Técnicas baseadas em dados de água superficial 25

2.2.1.1. Balanço hídrico de canal 26

2.2.1.2. Medidas de drenagem em leitos de corpos d'água superficiais 27

2.2.1.3 Fluxo de base através da separação da hidrógrafa 27

2.2.1.4. Traçadores 29

2.2.1.5. Modelagem Numérica 30

2.2.2 Técnicas baseadas em dados da zona não saturada 30

2.2.2.1 Lisímetros 31

2.2.2.2 Plano de fluxo zero 31

2.2.2.3 Lei de Darcy 32

2.2.2.4 Traçadores 33

2.2.2.5 Modelagem numérica 34

2.2.3 Técnicas baseadas em dados da zona saturada 35

2.2.3.1 Método da variação do nível freático 35

2.2.3.2 Lei de Darcy 36

2.2.3.3 Traçadores 36

2.2.3.4 Modelagem numérica $\quad 37$

2.3. Relação entre recarga subterrânea e explotação de água subterrânea 
2.4. Alguns casos de modelagem numérica aplicada a estudos de avaliação de recarga e sustentabilidade de recursos hídricos subterrâneos

2.4.1 Aqüífero do Alto Vale de Santiago, Chile 44

2.4.2 Aqüífero da bacia do Rio Küçük Menderes, Turquia Ocidental 46

2. 4.3 Swidinica, Polônia 48

2.4.4 Baixada do Rio São Lourenço, Quebec, Canadá 49

2.4.5 Aqüífero Ogallala, em Kansas $\quad 51$

3. O caso da Bacia Hidrográfica do Rio São Domingos, sub-bacia de Barro Branco

3.1 Bacia Hidrográfica do Rio São Domingos 53

3.1.1 Localização 53

3.1.2 Clima 53

3.1.3 Geologia $\quad 55$

3.1.3.1 Geologia Regional 55

3.1.3.2 Geologia Local 56

3.1.4 Geomorfologia 60

$\begin{array}{ll}3.1 .5 \text { Solos } & 60\end{array}$

3.1.6 Uso e Ocupação da Terra $\quad 61$

$\begin{array}{ll}3.2 \text { Micro-bacia de Barro Branco } & 67\end{array}$

3.2.1 Descrição da área $\quad 67$

$\begin{array}{ll}3.2 .2 \text { Geologia } & 67\end{array}$

$\begin{array}{ll}3.2 .3 \text { Solos } & 77\end{array}$

$\begin{array}{ll}3.2 .2 \text { Uso da Terra } & 77\end{array}$

4. Metodologia 80

4.1 Modelo Conceitual 82

4.2 Modelo Numérico 82

4.2.1 Malha de Elementos Finitos 83

4.2.2 Dados de Entrada 84

4.2.3 Base de Dados de Rochas Fraturadas 85 
4.2.4 Dados Hidrológicos 86

4.2.5 Calibração 86

4.2.6 Análise de Sensibilidade $\quad 87$

4.2.7 Simulação de Cenários de Bombeamento 87

5. Modelo conceitual de fluxo subterrâneo da micro-bacia de Barro

Branco 88

5.1 Descrição do Domínio 88

$\begin{array}{ll}5.2 \text { Condições de Contorno } & 91\end{array}$

5.3 Condições Iniciais 92

5.4 Parâmetros de fluxo 93

5.4.1 Condutividade Hidráulica 93

5.4.2 Coeficiente de Armazenamento 96

5.4.3 Coeficiente de Transferência ou de Drenança 96

5.4.4 Parâmetros de fluxo não saturado 97

$\begin{array}{ll}5.5 \text { Recarga } & 100\end{array}$

6. Modelo numérico de fluxo subterrâneo de Barro Branco 110

6.1. Equações de Fluxo 111

6.2. Malha de Elementos Finitos 112

6.3. Dados de Entrada 114

6.3.1 Condições Iniciais 114

6.3.2 Condições de contorno 115

6.3.3 Parâmetros de Fluxo 116

$\begin{array}{ll}\text { 6.3.4 Recarga } & 117\end{array}$

6.4. Calibração 117

$\begin{array}{ll}6.5 \text { Verificação da calibração } & 128\end{array}$

6.6 Análise de sensibilidade 132

$\begin{array}{ll}6.6 .1 \text { Recarga } & 134\end{array}$

6.6.2 Condutividade Hidráulica 138

6.6.3 Carga hidráulica de referência dos rios 140 
6.7 Apresentação e análise dos resultados 143

6.7.1 Distribuição da carga hidráulica e posição do nível freático 143

6.7.2 Estimativas de recarga e balanço de massa 160

6.7.3 Estimativas de vazão 163

6.8 Vazões efluentes e vazão sustentável 164

7. Cenários simulados de bombeamento 166

$\begin{array}{ll}7.1 \text { Cenário } 1 & 167\end{array}$

7.2 Cenário $2 \quad 171$

7.3 Cenário $3 \quad 174$

$\begin{array}{ll}7.4 \text { Cenário } 4 & 178\end{array}$

7.5 Cenário 5

7.6 Cenário $6 \quad 185$

$\begin{array}{ll}7.7 \text { Análise dos Resultados } & 189\end{array}$

8. Conclusões e Considerações Finais 197 
Olha, que chuva boa, prazenteira que vem molhar minha roseira, chuva boa, criadeira, que molha a terra, que enche o rio, que limpa o céu, que traz o azul

Olha, o jasmineiro está florido e o riachinho de água esperta se lança embaixo do rio de águas calmas

Tom Jobim, Chovendo na Roseira 